\title{
Entdeckung eines neuen Planeten (124) und Beobachtungen der Planeten (122) und (123).
}

Litchfield Obs. of Ham. Coll. Clinton, N. Y., 1872, Aug. 26.

Am 23. August fand ich einen Planeten, hell 10ter Grösse, der wohl die № 124 tragen wird. Folgende Beobachtungen habe ich davon erhalten:

\begin{tabular}{|c|c|c|c|c|c|c|c|c|}
\hline 1872 & Ham. Coll. m. Zt. & & $\alpha(12$ & & & (124) & & Anzahl Vgl. \\
\hline ug. 23 & $12^{\mathrm{h}} 28^{\mathrm{m}}$ & $22^{\mathrm{h}}$ & $21^{\mathrm{m}}$ & $23^{s} 61$ & $-7^{\circ}$ & $18^{\prime} 2$ & $28^{\prime \prime} 8$ & 10 \\
\hline - & $\begin{array}{lll}13 & 22 & 50\end{array}$ & & 21 & 21.66 & & 184 & 42.3 & 5 \\
\hline 25 & 12 & 22 & 19 & 44.45 & -7 & 30 & 13.4 & 10 \\
\hline
\end{tabular}

Im Anschluss an die neulich mitgetheilten Beobachtungen folgen hier noch die später gelungenen von den beiden Planeten des 31 . Juli.

\begin{tabular}{|c|c|c|c|c|c|c|c|c|c|c|}
\hline \multirow[b]{2}{*}{ Aug. } & \multirow[b]{2}{*}{9} & & & & \multicolumn{3}{|c|}{$\begin{array}{l}\text { Planet (122) } \\
\alpha(122)\end{array}$} & \multicolumn{2}{|c|}{$\delta(122)$} & \multirow[b]{2}{*}{10} \\
\hline & & $11^{\mathrm{h}}$ & $28^{\mathrm{m}}$ & $53^{\mathrm{s}}$ & $21^{\mathrm{h}}$ & $42^{\mathrm{m}}$ & 14.02 & $-12^{\circ}$ & $16^{\prime} \quad 5.7$ & \\
\hline$n$ & 21 & 11 & 51 & 19 & & 33 & 57.90 & 13 & $4 \quad 32.2$ & 10 \\
\hline$\Rightarrow$ & 23 & 9 & 23 & 28 & 21 & 32 & 36.05 & -13 & 1157.6 & 10 \\
\hline & & & & & & $\begin{array}{l}\operatorname{lane} \\
\alpha(12\end{array}$ & t $(123)$ & & (123) & \\
\hline Aug. & 9 & $12^{h}$ & $29^{\mathrm{m}}$ & $53^{h}$ & 21 & $50^{\mathrm{m}}$ & $43^{s} 10$ & $-10^{\circ}$ & $20^{\prime} 26.7$ & 6 \\
\hline$"$ & 21 & 13 & 56 & 58 & & 39 & 44.56 & & $48 \quad 39.2$ & 10 \\
\hline & 23 & 10 & 21 & 15 & 21 & 38 & 4.67 & 10 & $\begin{array}{ll}53 & 19,5\end{array}$ & 10 \\
\hline
\end{tabular}

Sämmtliche Beobachtungen sind mittelst des Fadenmikrometers gemacht.

10

10

C. H. F. Peters.

\section{Entdeckung eines neuen Planeten (125) durch Herrn I osper - Henry in Paris.}

(Pariser Bulletin No 65.)

1872 September $11 . \quad 15^{\mathrm{h}} 47^{\mathrm{m}} 35^{\mathrm{s}} \mathrm{m}$. Zt. Pr is.

$$
\mathrm{AR}=23^{\mathrm{h}} 59^{\mathrm{m}} 33^{\mathrm{s}} . \quad \text { Decl. }=-0^{0} \quad 35^{\prime} 57^{\prime \prime}
$$

Stündl. Bew. in $\mathrm{AR}=-1^{\mathrm{s}} 9$ in Decl. $=-2 c^{\prime}$.

Grösse 11.7 .

\section{I $\mathrm{n} \mathrm{h}$ h a l $\mathbf{l}$ t.}

(Zu Ar 1902.) Ueber die Frrben der Fixsterne, II. 81. - Mittlere Declinationen von 57 Fundamentalsternen, abgeleitet ans Leidener Meridiankreisbeouachtungen in den Jahren $1864-1868,93$.

(Zu $\mathrm{N}$ 1903.) Ueber die verschiedenen Methoden zur Bestimmung der Sonnenparallaxe nnd die in neuerer Zeit nach derselben gefundenen Resultate, 97. - Beobachtungen der Planeten (122) nnd (123), 111.

(Zu ji 1904.) F. Zöllner, Ueber die electrische und magnetische Fernewirkung der Sonne, 113. - Schreiben des Herrn Professors Dr. $\boldsymbol{R}$. Wolf an den Herausgeber, 123. - Maximum von Mira Ceti. 1872, 125. - Entdeckung eines neuen Planeten (124) und Beobachtungen der Planeten (122) und (123), 127. - Entdeckung eines neuen Planeten (125) durch Herrn Prosper-Henry in Paris, 127. 